\title{
Expression of drought tolerance in transgenic cotton
}

\author{
Zeeshan Shamim, Bushra Rashid*, Shahid ur Rahman, Tayyab Husnain \\ Centre of Excellence in Molecular Biology, University of the Punjab, 87-W Canal Bank Road, \\ Thokar Niaz Baig, Lahore-53700, Pakistan
}

*Corresponding author, e-mail: bush_rashid@yahoo.com

Received 13 Feb 2012

Accepted 15 Nov 2012

\begin{abstract}
Tolerance against drought in T1 progeny of transgenic cotton (Gossypium hirsutum) previously transformed with GHSP26 (Heat Shock Protein Gene), GUSP1 (Universal Stress Protein Gene), and Phyto-B (Phytochrome-B Gene) was investigated at the vegetative, squaring, and boll formation stage. Detection of transgenes into the progeny plants through PCR showed a Mendelian inheritance pattern (3:1). Real-time PCR quantified the expression of GHSP26 as transgenic plants which tolerated drought stress for 10-12 days at an average of 18 fold more at the vegetative stage which was increased to 19 fold at the squaring stage, while control plants withstood drought period only for 6 days. The gene expression was reduced to 13-fold more (13-15 days) in transgenic lines on an average basis as compared to control plants. Expression of GUSP1 in transgenic progeny at the vegetative and squaring stage was quantified as 22 fold more (11-13 days) and decreased to 15 fold when compared to the control plants which withstood the drought period only for 6 days. Average relative fold expression of Phyto-B transgene as compared to the control was 0.67 more ( 8 days) at the vegetative stage. Thereafter, expression was elevated to 0.85 fold under drought stress conditions at squaring stage and continued to increase to 3.5 fold higher (14-15 days) at boll formation stage when compared to that of control plants. Most notably, the number of bolls per plant, single boll weight, and seed cotton yield of our transgenic lines were greater than those of non-transgenic plants under drought stress, which is of immense worth.
\end{abstract}

KEYWORDS: Gossypium hirsutum, water stress, transgenic inheritance, heat shock protein, universal stress protein, Phyto-B gene

\section{INTRODUCTION}

Cotton is an important crop in the world due to its most valuable fibre production and oilseeds ${ }^{1}$. The genus Gossypium contains about 50 diverse species, four of which are cultivated. G. hirsutum L. and G. barbadense L. are tetraploid $(2 n=4 x=52)$ and $G$. arboreum L. and G. herbaceum L. are diploid $(2 n=2 x=26)$. There is $5 \%$ reduction in the cotton yield due to various reasons, including shortage of irrigation water ${ }^{2}$.

The diploid cotton species is not only the reservoir of important biotic and abiotic stress resistance genes, but it also offers better opportunities to study gene structure and function through techniques of gene knockouts $^{3}$. As compared with classical breeding, transgenic technology not only introduced valuable genes into cotton and other agriculturally important crops, but also made it possible to study function and regulation of such genes ${ }^{4,5}$.

Abiotic stresses, such as drought, salinity, and heat, currently have a massive impact on crop productivity and agricultural supply. Global water scarcities and quality issues are reaching crisis proportions not only in developing countries but across the world ${ }^{6}$. It is revealed that low yield of certain crops resulting from water scarcity demands the use of modern/advanced biological techniques to resolve this problem. Recently, research into the molecular mechanisms of stress responses has started to bear fruit and, in parallel, genetic modification of stress tolerance has also shown promising results that may ultimately apply to agriculturally and ecologically important plants ${ }^{7}$. Under drought stress, plants generally display many physiological responses which result in accumulation of certain differentially, expressed gene products ${ }^{8-10}$. Drought is also the major limiting factors for fibre and lint quality after flowering. Therefore it is important to understand the genes expressed during drought stress ${ }^{11}$ and ultimately we will require drought resistant cotton varieties.

Genes that have been successful in improving drought tolerance include those encoding heat-shock proteins (HSPs). These chaperones play a crucial role in protecting plants against stress by re-establishing normal protein conformation and thus normal cellular homeostasis $^{12,13}$. The Universal Stress Protein (USP) super-family encompasses an ancient and conserved 
group of proteins that are found in bacteria, archaea, fungi, flies, and plants ${ }^{14}$. These proteins GUSP1 and GUSP2 show specific expression patterns during drought stress ${ }^{15,16}$.

Light play a fundamental role in the existence of plants as a wide array of genes is transcriptionally regulating the circadian clock in Arabidopsis thaliana ${ }^{17}$. So phytochrome controls the transition from vegetative to reproductive growth, seedling establishment, and entrainment of circadian clock ${ }^{18,19}$. The primary photoreceptors involved in regulating the red/far-red light-induced responses are the phytochrome pigments. Phytochrome A (PHYA) is a light-liable phytochrome that predominates in dark-grown tissues whereas PHYB is light stable and predominates in light-grown tissue. The other Phytochromes (PHYC, PHYD, and PHYE) are also light stable and have complex overlapping and differential roles relative to PHYA and PHYB.

The present study has been conducted to assess the overexpression of the transgenes GUSP1, GHSP $26^{20}$, and Phytochrome- ${ }^{21}$ which had been driven under the $C a M V 35 S$ promoter and previously transformed in cotton (G. hirsutum). Over expression of genes in the transgenic progeny plants at three different growth stages (vegetative, squaring, and boll formation) has been studied under drought stress condition.

\section{MATERIAL AND METHODS}

\section{Seed source, sterilization, and germination}

Seeds of T1 transgenic progeny of $G$. hirsutum previously transformed with GUSP1, GHSP26, and Phyto- $B$ genes were obtained from seed bank of Centre of Excellence in Molecular Biology, Lahore, Pakistan (GUSP1, GHSP $26^{20}$, and Phytochrome- ${ }^{21}$ ). The plasmid construct used in this study was made as pCambia 1301 T-DNA region contained a GUS gene along with hygromycin plant selection gene driven by the CaMV $35 S$ promoter. Lint was removed from the seeds with concentrated $\mathrm{H}_{2} \mathrm{SO}_{4}$ and washed with tap water. The seeds which floated at the surface of water were discarded. Seeds sterilization was done by using $0.1 \% \mathrm{HgCl}_{2}$ for $5-10 \mathrm{~min}$ followed by 5 washings with autoclaved distilled water and kept for germination in dark at $30^{\circ} \mathrm{C}$ on moist filter paper for 72 h. After germination seedlings were grown in composite soil (soil, sand, peat moss 1:1:1) for 40 days in green house at $30 \pm 2{ }^{\circ} \mathrm{C}$ and relative humidity near $50 \%^{22}$. Metal halide illumination lamps $(400 \mathrm{~W})$ were used to supplement natural radiation. Light radiation reached a maximum of $1500 \mu \mathrm{mol} \mathrm{m} \mathrm{s}^{-1}$ at the top of canopy at midday. Complete randomized design was used for this study.

\section{Amplification of foreign genes through PCR in progeny of transgenic cotton}

Transgenes (GUSP1, GHSP26, and Phyto-B) were amplified through polymerase chain reaction (PCR) in the $\mathrm{T} 1$ progeny of transgenic cotton plants. This was done only for the initial screening for amplification of the foreign genes into the transgenic plants. For this purpose genomic DNA was isolated as described earlier $^{23}$ with some modifications. The sequence of GUSP1 primer was F 5'-CTTCGACTGTATCTTG CTCATTTTC- $3^{\prime}$ and R 5'-CCAAAGCTGGATTC CATATTAGAAG-3', that of GHSP26 was F $5^{\prime}-\mathrm{GG}$ CTGAGCATCTGGTAGCTT- $3^{\prime}$ and R $5^{\prime}$-AATCC AAACCGTGGACAATG- $3^{\prime}$, and that of Phyto-B, F $5^{\prime}$-GGATCATGGTTTCCGGAGTCGG-3' and R 5'-GGATCTAATATGGCATCATCAGCA-3'. The PCR was carried out with the above primers to amplify the $710 \mathrm{bp}, 510 \mathrm{bp}$ and $646 \mathrm{bp}$ fragments of GHSP26, GUSP1 and Phyto-B genes, respectively. PCR reactions were performed in volume of $25 \mu \mathrm{l}$ with 2.5 U Taq DNA Polymerase, 0.2 mM dNTP's, 10 pM of each primer, and $50 \mathrm{ng}$ of DNA template. The PCR temperature to amplify GHSP26 and GUSP1 genes was kept at $94{ }^{\circ} \mathrm{C}$ for $4 \mathrm{~min}, 94^{\circ} \mathrm{C}$ for $30 \mathrm{~s} 60^{\circ} \mathrm{C}$ for $30 \mathrm{~s}$, and $72^{\circ} \mathrm{C}$ for $1 \mathrm{~min}$ followed by 40 times. PCR temperature to amplify Phyto-B gene was kept at $95^{\circ} \mathrm{C}$ for $4 \mathrm{~min}, 94^{\circ} \mathrm{C}$ for $45 \mathrm{~s}, 56^{\circ} \mathrm{C}$ for $45 \mathrm{~s}$, and $72^{\circ} \mathrm{C}$ for $1 \mathrm{~min}$ followed by 40 times. PCR products were resolved on $1 \%$ agarose gel and observed under UV light.

\section{Drought stress treatment to transgenic plants and inheritance studies}

To evaluate the temporal gene expression of candidate genes for drought tolerance, transgenic and non transgenic plants were kept without watering for maximum 15 days for drought stress treatments. First drought stress was applied to the plants at vegetative growth stage (after 40-45 days of germination), second drought stress was applied at square formation stage (55-60 days old plants) and third drought stress was applied at boll formation stage (120-130 days old plants). Chi square $\left(\chi^{2}\right)$ test was also applied for inheritance of the candidate genes in T1 progeny of the transgenic plants (Table 1).

\section{Total RNA extraction and cDNA synthesis}

Total RNA was extracted as the method described earlier with some modifications ${ }^{24}$. Fresh young leaf samples were taken from the main terminal branch 
Table 1 Inheritance studies of foreign genes in T1 transgenic cotton progeny after drought stress treatment.

\begin{tabular}{llccc}
\hline Gene & $N$ & $O$ & $E$ & $\chi^{2}$ \\
\hline GHSP26 & 21 & 14 & 15.75 & 0.78 \\
GUSP1 & 32 & 23 & 24.00 & 0.17 \\
Phyto-B & 14 & 10 & 10.50 & 0.10 \\
\hline
\end{tabular}

$N$ : total number of plants. $O$ : drought tolerant plants. $E$ : expected drought tolerant plants.

$\chi^{2}=\sum(O-E)^{2} / E$. The calculated value is in all the cases less than the tabulated value for dof $=1$ at $5 \%$ level of probability (3.84), showing the inheritance of these genes in accordance with Mendelian ratio for single gene inheritance $(3: 1)$.

parts and used for RNA extraction. RNA was quantified with the help of Nanodrop ND-1000 spectrophotometer by measuring absorbance at $260 \mathrm{~nm}$ and $280 \mathrm{~nm}$ wavelength. RNA quality was checked by resolving the sample on $1 \%$ agarose gel. cDNA was synthesized by using Fermentas cDNA synthesis kit (Cat \# 1632).

\section{Quantitative real-time PCR}

The primers used for real-time PCR for GUSPl were F 5'-TCGGAGTTCAGAGAGAAGGAAG-3' and $\mathrm{R}$ 5'-CTGGCATCACCCCAGTAAAT-3', for GHSP26, F 5'-CCTAAACGGTTGGCTATGGA-3' and R 5'-TGTCATTGCGTCCTCGAATA-3', and for Phyto-B, F 5'-CTCCTGGCTGAGTTTCTGC T- $3^{\prime}$ and R $5^{\prime}$-GCTTGTCCACCTGCTGCTAT- $3^{\prime}$. Real-time PCR reactions were carried out with iQ5 cycler (BIO-RAD) in 96-well plate using the IQTM SYBR Green Super Mix. Different concentrations of the plasmid containing P2T1-4 were used as standard to validate the $\mathrm{iQ5}$ Cycler reaction and to determine the range of quantification (standard curve). cDNA $(50 \mathrm{ng})$ from the transgenic cotton plants transformed with GUSP1, GHSP26 and Phyto-B genes was used at vegetative, squaring and boll formation stages of plant growth. The reaction conditions for genes GHSPl and GUSP26 were as follows: denaturation at $95^{\circ} \mathrm{C}$ for $5 \mathrm{~min}$, followed by 40 cycles of denaturation at $94{ }^{\circ} \mathrm{C}$ for $30 \mathrm{~s}$, annealing at $60{ }^{\circ} \mathrm{C}$ for $30 \mathrm{~s}$, and extension at $72{ }^{\circ} \mathrm{C}$ for $40 \mathrm{~s}$, and final elongation step at $72{ }^{\circ} \mathrm{C}$ for $10 \mathrm{~min}$. For Phyto-B: denaturation at $95^{\circ} \mathrm{C}$ for $3 \mathrm{~min}$, followed by 40 cycles of denaturation at $94^{\circ} \mathrm{C}$ for $45 \mathrm{~s}$, annealing at $56^{\circ} \mathrm{C}$ for $30 \mathrm{~s}$, and extension at $72^{\circ} \mathrm{C}$ for $1 \mathrm{~min}$, and final elongation step at $72{ }^{\circ} \mathrm{C}$ for $10 \mathrm{~min}$. Melting curve was analysed by continuous monitoring of fluorescence between $60^{\circ} \mathrm{C}$ and $95^{\circ} \mathrm{C}$ with $0.5^{\circ} \mathrm{C}$ increments after every $30 \mathrm{~s}$. Cotton glyceraldehyde3-phosphate dehydrogenase (GAPDH) house-keeping gene was used as a control. Gene specific primers were designed using BIOEDIT software.

\section{Effect of drought stress on yield}

Productivity of transgenic cotton progeny was estimated as number of bolls per plant was counted, average single boll weight was measured and seed cotton yield per plant was hand collected. Seed cotton was collected, dry petals and trash was removed and the yield per plant was measured by weighing balance.

\section{RESULTS AND DISCUSSION}

Prevalence of drought stress is inconsistent under field conditions and plants may perhaps be exposed to this abiotic stress at any time throughout their life. Cotton is comparatively drought-tolerant, but severe water losses can slowdown plant maturity, affecting bolls and ultimately reduce yield. This study demonstrates that cotton plants of transgenic lines of progeny transformed with GUSP1, GHSP26, and Phyto- $B$ genes, showed improved drought tolerance at three plant growth stages (vegetative, squaring, and boll formation) that are key water stress periods during plant growth. All the transgenic lines showed germination $60-100 \%$.

\section{Amplification of foreign genes in the T1 progeny of transgenic cotton plants}

PCR showed the amplification of GHSP26 gene in T1 transgenic progeny of transgenic cotton (Fig. 1a). Out of 21 plants, 14 showed amplification of $710 \mathrm{bp}$ fragment of this gene. GUSP1 gene was also amplified in the progeny plants in the form of $510 \mathrm{bp}$ with full length primers (Fig. 1b). Out of 32 plants, 23 were confirmed for the amplification of GUSP1 gene. Similarly PCR confirmed the amplification of Phyto-B gene in T1 progeny (Fig. 1c) and out of 7 plants, 6 amplified the 646 bp fragment of Phyto-B gene. Plasmid construct used in this study was made as pCambia 1301 T-DNA region contained a GUS gene along with hygromycin plant selection gene driven by the $C a M V 35 S$ promoter.

\section{Drought stress treatment to transgenic plants and inheritance studies}

Although this study is based on the analysis of T1 generation which is expected not to be homozygous, but it was done to investigate the initial studies related to inheritance and integration of the transgenes into the progeny plants. According to Mendelian inheritance pattern for gene integration, the ratio of 


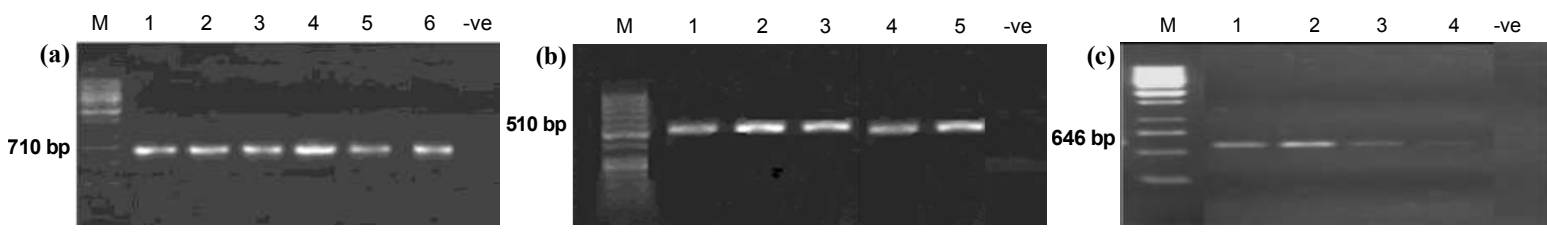

Fig. 1 PCR amplification of different drought tolerant genes in T1 transgenic cotton lines. (a) PCR product of GHSP26 from transgenic plants. Lane $\mathrm{M}$ is a $1 \mathrm{~KB}$ DNA ladder, lanes 1-6 transgenic plants, -ve negative control. (b) PCR product of GUSP1 from transgenic plants. Lane M is a 50 bp DNA ladder, lanes 1-5 transgenic plants, -ve negative control. (c) PCR product of Phyto-B from transgenic plants. Lane M is a $1 \mathrm{~KB}$ DNA ladder, lanes 1-4 transgenic plants, -ve negative control.

transgene containing plants to control or non transgenic ones should fit the expected $3: 1$ in T1 generation, which was also consistent with our statistical results. It is probably due to random chance or for some other factors influencing the experimental results (Table 1). There are many reports in context of inheritance and expression stability of foreign incorporated genes in transgenic crops. The previous studies revealed consistent Mendelian ratios for single gene inheritance in certain crops like, alfalfa ${ }^{25}$, rice $^{26}$, maize $^{27}$, cotton ${ }^{28-31}$, and in cow pea ${ }^{32}$. However, in many cases, instead of Mendelian segregation, the complicated segregation profiles for the genes have also been reported ${ }^{33-38}$. Nevertheless, in the present study, Mendelian ratio of single gene inheritance was followed.

\section{GHSP26 gene expression}

For temporal gene expression pattern studies, total RNA was extracted from leaves under drought stress condition at different growth stages, Vegetative stage (after 40-45 days germination), Square formation (after 55-60 days germination) and Boll formation (after 120-130 days germination). The products were visualized as a smear along with two distinct ribosomal RNA bands, $28 \mathrm{~S}$ and $18 \mathrm{~S}$. Real-time PCR detected the expression level of foreign genes in the transgenic progeny. Different lines exhibited different gene expression in response to drought stress at vegetative stage. An optimum cotton crop at 40 days after planting is thought to be a picture of health. In addition to being drought stress-free, the crop would exhibit healthy leaves, with roots extending into the row middles, and plants growing rapidly and uniformly. Among 6 lines of the GHSP26 transformed lines, line 5 on average basis showed maximum tolerance (12 days) to the drought stress showing maximum expression (30 fold expression) of GHSP26 followed by line 3 and 6 which contended drought for 10 days each, while control (nontransgenic) withstood drought period only for 6 days
(Fig. 2a, b). Following the formation of first reproductive branch, new branches will develop every 3 days after approximately. The first square is formed on the lowest reproductive branch of the plant. Drought tolerance was continued to increase at squaring stage, line 5 on average basis showed maximum tolerance (12 days) and exhibited maximum expression (34 fold expression) of HSP26 followed by line 3 and 1 which endured for 10 days each as compared to 6 days of control (non-transgenic under the aforesaid conditions) (Fig. 2c, d).

After fertilization, seeds are developed in a cell like structure, called boll. First bolls generally begin to open 125-130 days after sowing and irrigation during this period is thought to be critical. Transformed lines were once again subjected to drought stress and expression of gene at boll formation revealed that transgenic line 5 on average basis showed maximum drought tolerance (15 days) showing maximum expression (22 fold expression) of HSP26 followed by line 1 and 3 which endured for 14 and 13 days, respectively, (Fig. 2e, f). Control (non-transgenic) tolerated drought stress for 7 days. Expression of GHSP26 has been found reduced with the plant growth and found at peak at earlier stage ${ }^{39-41}$, which is in contrast to previous reports ${ }^{7,42}$ as the elevated expression of Taldo1 gene at lateral stage of plant growth was observed as compared to juvenile stage where the expression level was very less but this change in gene expression could be genotype dependent.

\section{GUSP1 gene expression}

Universal stress protein play role in survival of cells affected by different abiotic stresses ${ }^{43}$. Progeny of transformed lines consists of GUSP1 subjected to drought stress at vegetative stage and among 10 lines of the GUSP1 transformed lines, line 1 on average basis showed maximum tolerance (13 days) to the drought showing maximum expression (70 fold expression) of GUSP1 (Fig. 3a, b) followed by line 6 and 8 which contended for 11 and 10 days, respectively, 

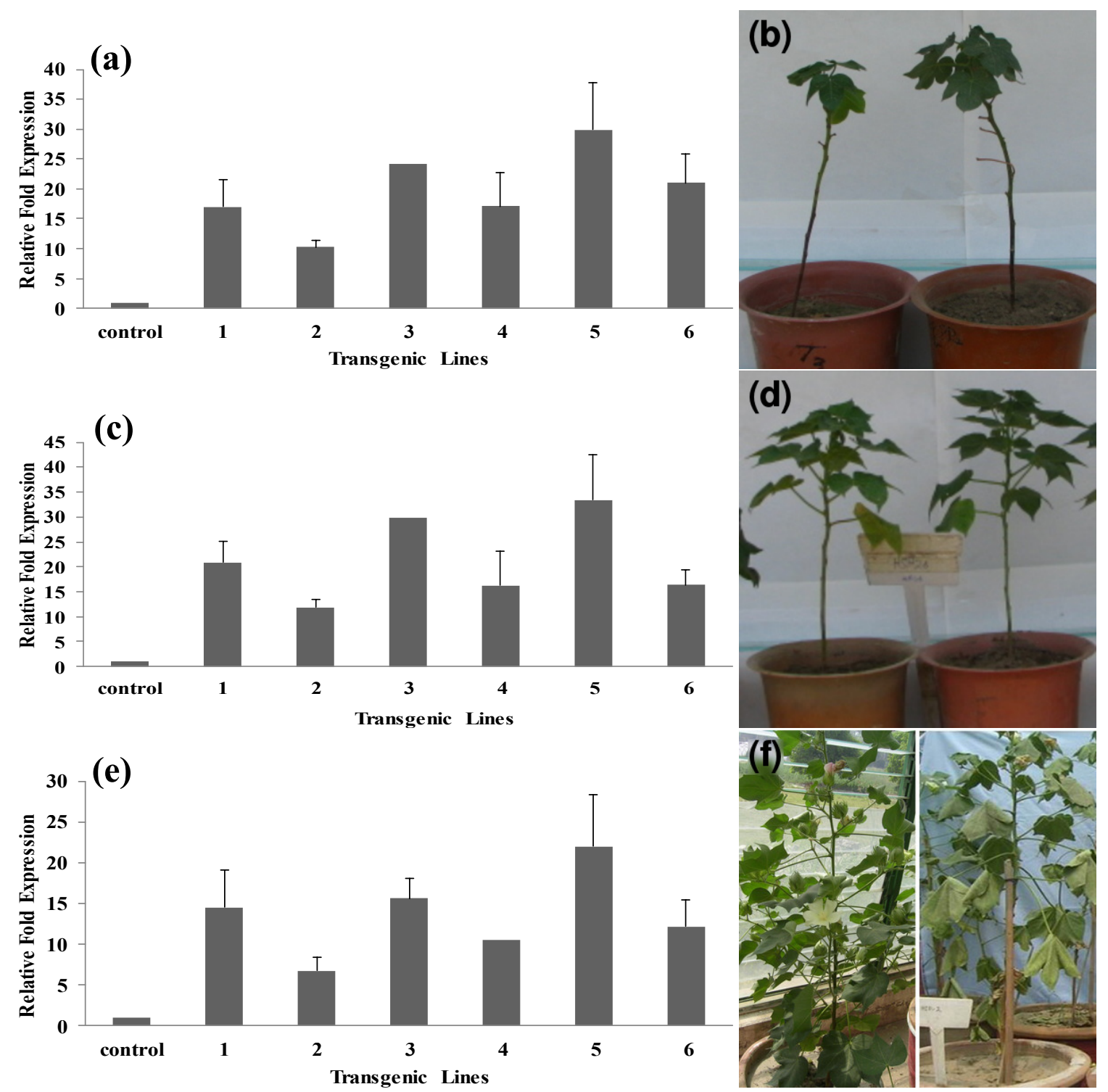

Fig. 2 Relative fold expression of GHSP26 in T1 progeny and transgenic cotton plants at different growth stages. Expression of GHSP26 in leaves at (a) vegetative stage, (c) squaring stage, and (e) boll formation, and phenotype of transgenic (right) and control (left) plants at (b) vegetative stage, (d) squaring stage, and (f) boll formation stage. Plants were kept under water withheld condition for 15 days at each developmental stage. The data was normalized with reference to GAPDH (Glyceraldehyde 3-phosphate dehydrogenase) as internal control. The solid bars are the standard deviation calculated from three repeats.

while control (non-transgenic) withstood drought period only for 6 days. After the vegetative stage, a temporal expression study of the drought tolerant GUSP1 gene was studied at the square formation stage. Different lines showed different level of gene expression in response to drought stress at this stage as well but among 10 lines of the GUSP1 transformed lines, line 1 on average basis showed maximum tolerance (12 days) to the drought and exhibited maximum expression (82-fold expression) of GUSP1 followed by line 6 and 8 which endured for and 11 days each as compared to 6 days of control (non-transgenic) under the aforesaid conditions (Fig. 3c, d). Transgenic lines exhibited different level of drought tolerance in response to drought stress at boll formation stage. Among 10 lines of the GUSP1 transformed lines, maximum drought tolerance (16 days) on average basis was observed in line 1 with maximum gene 

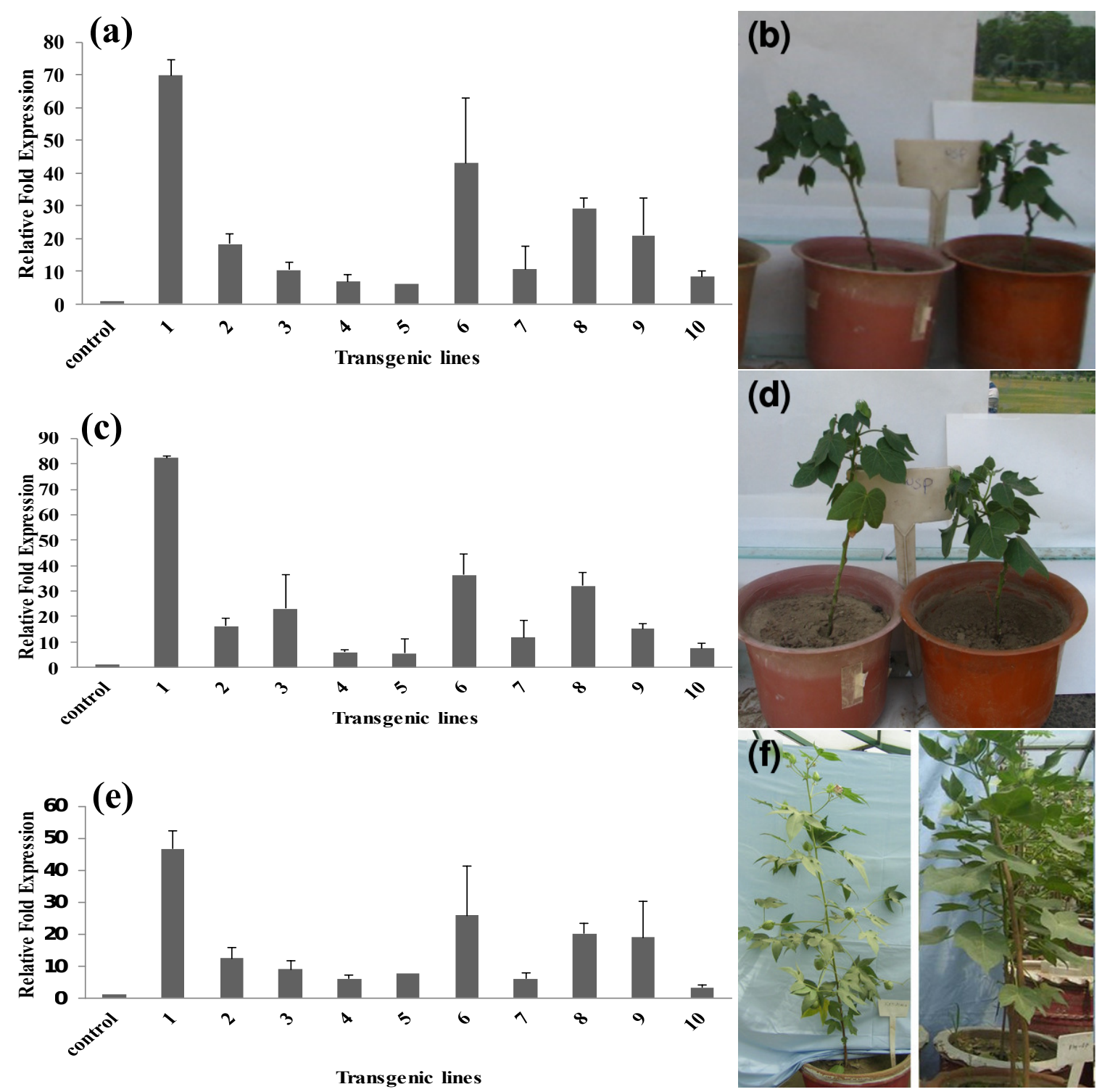

Fig. 3 Relative fold expression of GUSP1 in T1 progeny and transgenic cotton plants at different growth stages. Expression of GUSP1 in leaves at (a) vegetative stage, (c) squaring stage, and (e) boll formation, and phenotype of transgenic (right) and control (left) plants at (b) vegetative stage, (d) squaring stage, and (f) boll formation stage. Plants were kept under water withheld condition for 15 days at each developmental stage. The data was normalized with reference to GAPDH (Glyceraldehyde 3-phosphate dehydrogenase) as internal control. The solid bars are the standard deviation calculated from three repeats.

expression (47 fold expression) of GUSP1 followed by line 6 and 8 which endured for 14 days each (Fig. 3e, f). Control plants tolerated drought stress only for 7 days. As the expression of GUSP1 has found to be decrease with the advancement in plant growth but even then it has expressed and helped the plant to tolerate the drought which indicate that this gene might function as a switch in adaptation of drought stress. Possible explanation for elevated expression of GUSPI gene at earlier stages may be the meristematic activity of the plant ${ }^{44}$. Another reason may be the high copy number of transgene in transgenic plants ${ }^{45}$.

\section{Phyto-B gene expression}

Transgenic lines of Phyto-B were studied for gene expression in response to drought stress at vegetative stage. Among 2 lines of the Phyto-B transformed 

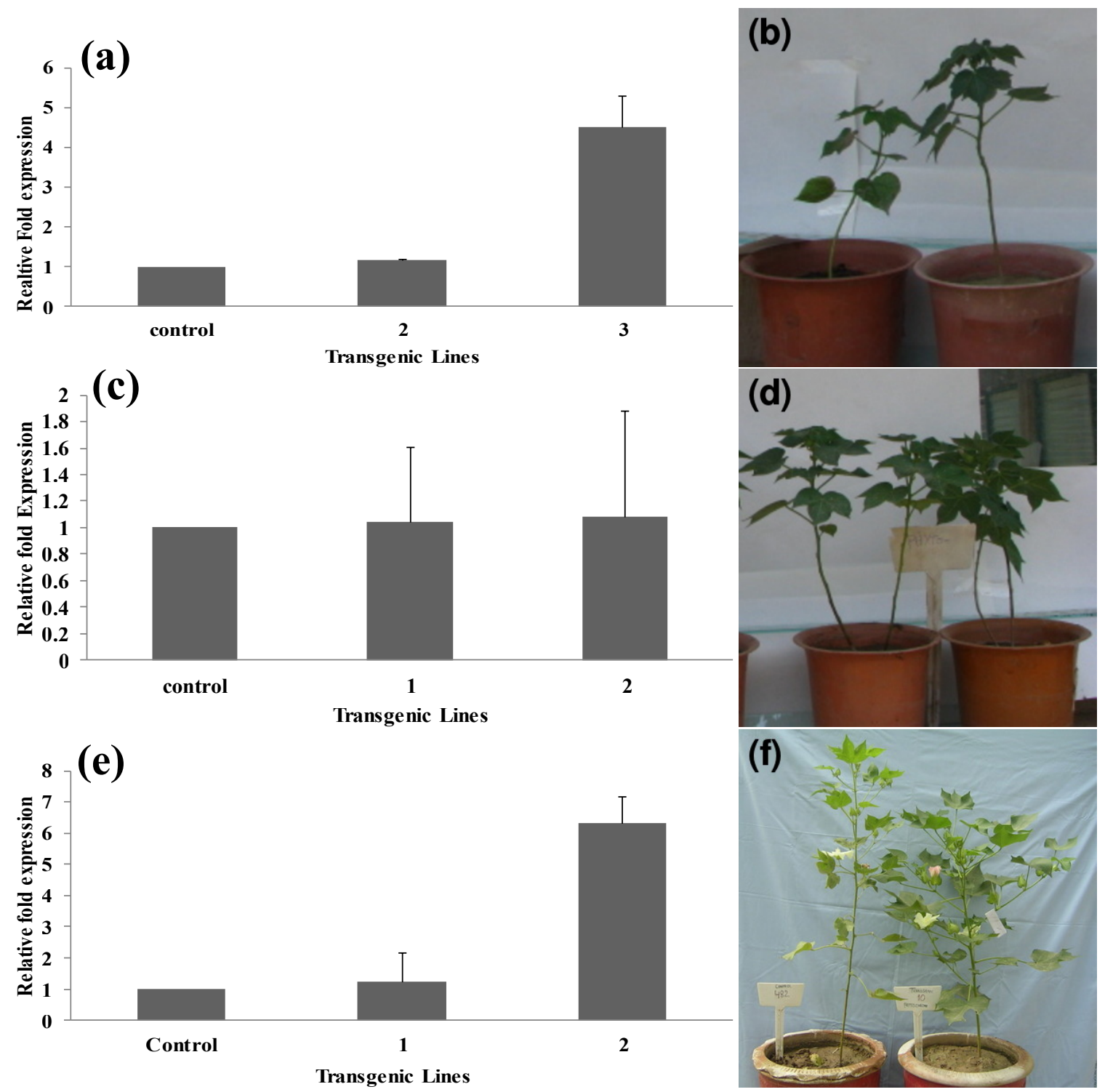

Fig. 4 Relative fold expression of PHYTO-B in T1 progeny and transgenic cotton plants at different growth stages. Expression of GUSP1 in leaves at (a) vegetative stage, (c) squaring stage, and (e) boll formation, and phenotype of transgenic (right) and control (left) plants at (b) vegetative stage, (d) squaring stage, and (f) boll formation stage. Plant kept under water withheld condition for 15 days at each developmental stage. The data was normalized with reference to GAPDH (Glyceraldehyde 3-phosphate dehydrogenase) as internal control. The solid bars are the standard deviation calculated from three repeats.

lines, line 2 showed maximum tolerance ( 8 days) to the drought stress showing maximum expression $(1.2$ fold expression) of Phyto-B (Fig. 4a, b) as compared to control which withstood drought tolerance only for 6 days.

Transgenic lines were subjected to drought stress at square formation stage and temporal analysis of the gene showed a little bit elevated expression pattern but almost equal expression as that of control under drought stress condition (Fig. 4c, d). This elevated expression was continued to increase in transgenic lines in response to drought stress for 14-15 days at boll formation stage. Line 2 on average basis showed 6.3 fold higher expressions as compared to that of control (non-transgene) (Fig. 4e, f).

Phytochrome may manipulate plant response to drought suggesting particular role in $\mathrm{ABA}$ regulation and stomatal conductance. Phyto-B gene restricts 


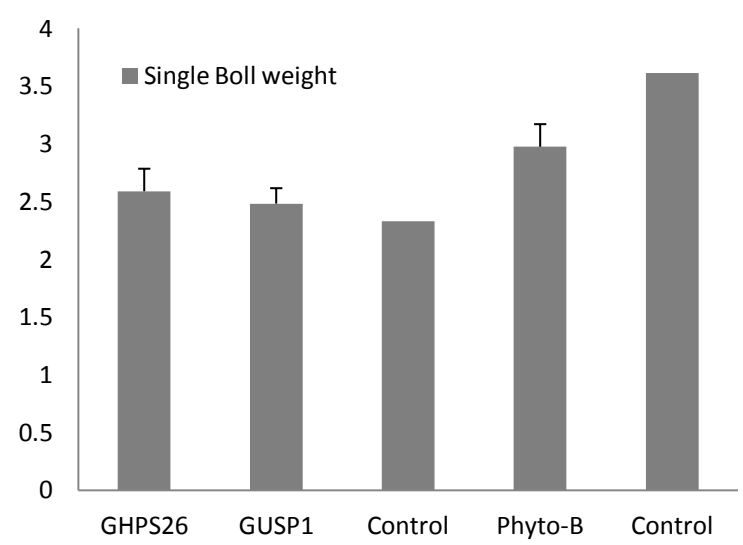

Fig. 5 Single boll weight of T1 cotton progeny transformed with GHSP26, GUSP1 and Phyto-B genes. The solid bars are the standard deviation calculated from three repeats.

the fruit shedding in cotton crop and fruit shedding is directly related to the production levels of $\mathrm{ABA}$, therefore it is assumed that certain phytochrome genes may suppress particular drought response under specific environment ${ }^{21,46}$. Gene expression of Phyto-B was higher at the latter plant growth stage and lower at the earlier stage similar as reported earlier ${ }^{12,42}$. Such difference in gene expression at different plant developmental stages may be due to strong influence of transcriptional activation of transgene, its site of integration and genotype dependence.

\section{Effect of drought stress on yield}

Application of plant biotechnology is one of the strategies for crop improvement and food production. The ultimate objective of this study is to get good yield even after the reduced irrigation and we observed that the number of bolls in transgenic plants have been increased as compared to non transgenic or control plants. The boll weight has also been increased on the transgenic lines as compared to the non-transgenic. Single boll weight of the transgenic progeny of plants transformed with GHSP26 and GUSP1 was increased by $23 \%$ and $36 \%$, respectively (Fig. 5 ). Interestingly the single boll weight of the transgenic progeny of Phyto-B was found a little bit reduced on transgenic progeny as compared to the control plants (Fig. 5). However, this reduction in boll weight is only $5 \%$. Phyto-B gene is reported to increased photosynthetic activity and enhancement of other physiological traits in plants, therefore it is assumed that the increased vegetative growth may have suppressed the boll formation process and ultimately the fold expression for drought tolerance at vegetative and boll formation,

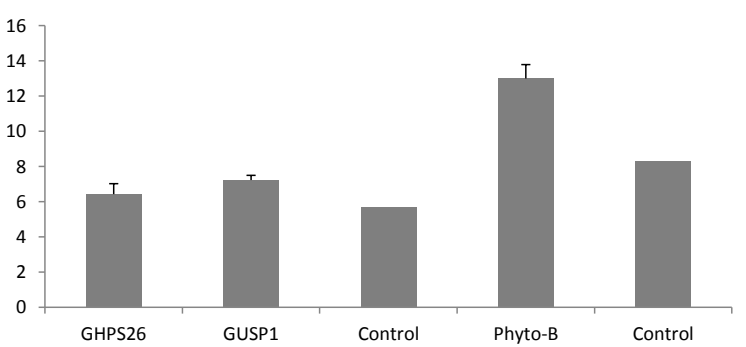

Fig. 6 Number of bolls of T1 cotton progeny transformed with GHSP26, GUSP1 and Phyto-B genes. The solid bars are the standard deviation calculated from three repeats.

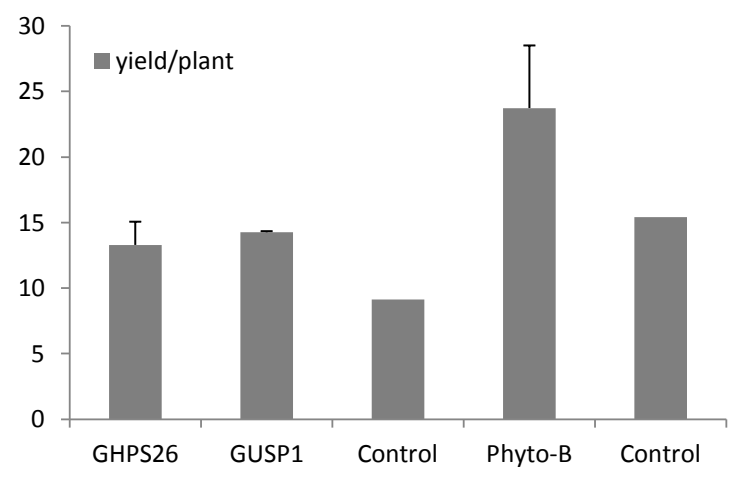

Fig. 7 Yield/plant of T1 cotton progeny transformed with GHSP26, GUSP1, and Phyto-B genes. The solid bars are the standard deviation calculated from three repeats.

respectively, is less (1.2 and 6.3) as compared to the GHSP26 and GUSP1. Number of bolls per plant of the transgenic progeny of GHSP26, GUSP1, and Phyto-B was found to be increased by $25 \%, 36 \%$, and $71 \%$, respectively, as compared to non-transgenic plants (Fig. 6). The data collected for the seed cotton yield per plant of the transgenic plants of GHSP26 of the same progeny was also found increased by $54 \%$ while compared with non-transgenic plants. In the same way seed cotton yield per plant for transgenic progeny of GUSP1 was increased by $63 \%$. Similarly the yield data for transgenic progeny of PHYTO-B showed an increase of $62 \%$ seedcotton yield per plant (Fig. 7). It has been observed that as the fold expression for drought tolerance is increased, the yield is also found to be increased which shows that the transgene is expressing at its maximum.

Seasonal variations affect the transgene expression in different cotton lines. This variation for the transgene efficacy is correlated with the promoter activity 47,48 . The other factors reported for variation 
in the level of gene expression, might be alteration in nucleotide sequence, gene integration point, copy number, cellular changes, and environmental factors $^{21,49}$. Transgenic plants expressing the drought tolerant genes are morphologically better and growing larger than the control plants under water withheld condition. Moreover, roots of GHSP26, GUSP1, and Phyto-B expressing plants expected to be larger than non transgenic plants. Therefore, fresh shoot and root biomass of transgenic plants may be higher than control plants. Three types of transgenic plants, when compared for the drought tolerance and the yield (in terms of single boll weight, number of bolls and seed cotton yield), it is observed that the GUSP1 is the best as showing 70-80 fold expression of drought tolerance for 13-12 days at vegetative and squaring stage, respectively, and 47 fold expression of drought tolerance for 16 days and yield was $63 \%$ in terms of seed cotton. Yield of other transgene expressing plants is also significantly higher than that of control plants after drought treatment. These results are consistent with the other reports as more bolls and fibre formation in the transgenic plants expressing AVP1 gene $^{50}$. Transcription factors also play an important role in abiotic stress tolerance mechanisms and so far a number of transcription factors have been found to be involved in abiotic stress tolerance pathways. Genes encoding transcription factors may considerably increase the drought tolerance by regulating (over expression or suppressing) the function of some genes.

Irrigation is very important after first blooming and by regulating the irrigation period after blooming yield could be increased ${ }^{51}$. Severe drought conditions affect the cotton plant's development and may cause small bolls and squares to shed. Improved maintenance of stomatal conductance under water stress ensures the higher photosynthesis, better growth and yield $^{52}$. Exogenous application of Glycinebetaine improves the growth and production of cotton plants under drought stress ${ }^{53}$.

In conclusion, most notably, the seed cotton yield of our transgenic lines was greater than that of nontransgenic plants under drought stress, which is of great worth. Therefore, it is expected that our results may promote strategies to improve crop yields in arid and semiarid areas.

\section{REFERENCES}

1. Zhang H, Guo C, Li C, Xiao K (2008) Cloning, characterization and expression analysis of two superoxide dismutase (SOD) genes in wheat (Triticum aestivum L.). Front Agr China 2, 141-9.
2. Economic survey of Pakistan (2010-11) Ministry of Finance, Pakistan, Agriculture Chapter.

3. Sakhanokho HF, Zipf A, Rajesekaram K, Saha S, Sharma GC, Chee PW (2004) Somatic embryo initiation and germination in diploid cotton (Gossypium arboreum L.). Vitro Cell Dev Biol Plant 40, 177-81.

4. Latham JR, Wilson AK, Steinbrecher RA (2006) The mutational consequences of plant transformation. J Biomed Biotechnol 2006, Article ID 25376.

5. Rodriguez-Uribe L, Higbie SM, Stewart JM, Wilkins T, Lindemann W, Sengupta-Gopalan C, Zhang J (2011) Identification of salt responsive genes using comparative microarray analysis in upland cotton (Gossypium hirsutum L). Plant Sci 180, 461-9.

6. Rodrigues FA, de Laia ML, Zingaretti SM (2009) Analysis of gene expression profiles under water stress in tolerant and sensitive sugarcane plants. Plant Sci 176, 286-302.

7. Wang W, Vinocur B, Altman A (2003) Plant responses to drought, salinity and extreme temperatures: towards genetic engineering for stress tolerance. Planta 2, 8, $1-14$.

8. Bray EA (1997) Plant responses to water deficit. Trends Plant Sci 2, 48-54.

9. Secenji M, Lendvai A, Hajósné Z, Dudits D, Györgyey J (2005) Experimental system for studying long-term drought stress adaptation of wheat cultivars. Acta Biol Szeged 49, 51-2.

10. Beck EH, Fetting S, Knake C, Hartig K, Bhattarai T (2007) Specific and unspecific responses of plants to cold and drought stress. J Biosci 32, 501-10.

11. Tripathy D, Klueva N, Wang J, Payton PR, Allen RD (2002) Transcription Profiling of drought stress induced expressed sequence tags during cotton boll formation. Amer Soci Plant Biolog Annu Meet 79, 42.

12. Wang W, Vinocur B, Shoseyov O, Altman A (2004) Role of plant heat-shock proteins and molecular chaperones in the abiotic stress response. Trends Plant Sci 9, 244-52.

13. Feder EM, Hofman GE (1999) Heat-shock proteins, molecular chaperons, and the stress response. Annu Rev Physiol 61, 243-82.

14. Kvint K, Nachin L, Diez A, Nystrom T (2003) The bacterial universal stress protein: function and regulation. Curr Opin Microbiol 6, 140-5.

15. Maqbool A, Zahur M, Irfan M, Qaiser U, Rashid B, Husnain T, Riazuddin S (2007) Identification, characterization and expression of drought related alphacrystalline heat shock protein gene (GHSP26) from Desi Cotton (Gossypium arboreum L.). Crop Sci 47, 2437-44.

16. Maqbool A, Zahur M, Irfan M, Barozai MYK, Rashid B, Husnain T, Riazuddin S (2008) Identification and Expression of six drought responsive transcripts through Differential Display in desi cotton (Gossypium arboreum). Mol Biol 42, 492-8.

17. Harmer SL, Hogenesch JB, Straume M, Chang H, Han 
B, Zhu T, Wang X, Kreps JA, et al (2000) Orchestrated transcription of key pathways in Arabidopsis by the Circadian Clock. Science 290, 2110-3.

18. Chen M, Chory J, Fankhauser C (2004) Light signal transduction in higher plants. Annu Rev Genet 38, 87-117.

19. Carvalho RF, Campos ML, Azevedo RA (2011) The role of phytochrome in stress tolerance. $J$ Integr Plant Biol 53, 920-9.

20. Maqbool A, Abbas W, Rao AQ, Irfan M, Zahur M, Bakhsh A, Riazuddin S, Husnain T (2010) Gossypium arboreum GHSP26 enhances drought tolerance in Gossypium hirsutum. Biotechnol Progr 26, 21-5.

21. Rao AQ, Bakhsh A, Nasir IA, Riazuddin S, Husnain T (2011) Phytochrome B mRNA expression enhances biomass yield and physiology of cotton plants. Afr J Biotechnol 10, 1818-26.

22. Rashid B, Husnain T, Riazuddin S (2004) In-vitro shoot tip culture of cotton (Gossypium hirsutum). Pakistan J Bot 36, 817-3.

23. Saha S, Callahan FE, Douglas AD, Creech JB (1997) Lyophilization of cotton tissue on quality of extractable DNA, RNA and protein. J Cotton Sci 1, 10-4.

24. Jaakola L, Pirttila AM, Halonen M, Hohtola A (2001) Isolation of high quality RNA from Bilberry ( $\mathrm{Vac}$ cinium myrtillus L.) fruit. Mol Biol 19, 201-3.

25. Micallef MC, Austin S, Bingham ET (1995) Improvement of transgenic alfalfa by backcrossing. Vitro Cell Dev Biol Plant 31, 187-92.

26. Duan X, Li X, Xue Q, Abo-El-Saad M, Xu D, Wu R (1996) Transgenic rice plants harbouring an introduced potato proteinase inhibitor II gene are insect resistant. Nat Biotechnol 14, 494-948.

27. Fearing PL, Brown D, Vlachos D, Meghji M, Privalle L (1997) Quantitative analysis of CryIA(b) protein expression in Bt maize plants, tissues and silage and stability of expression over successive generations. $\mathrm{Mol}$ Breed 3, 169-76.

28. Canming T, Jing S, Xiefi Z, Wangzhen G, Tianzhen Z, Jinlian S, Congfen G, Weijun Z, et al (2000) Inheritance of resistance to Helicoverpa armigera of 3 kinds of transgenic $B t$ strains available in upland cotton in china. Chin Sci Bull 45, 363-7.

29. Zhang BH, Liu F, Yao CB (2000) Plant regeneration via somatic embryogenesis in cotton. Plant Cell Tissue Organ Cult 60, 89-94.

30. Xia LH, He YR, Chun LU, Yang ZY, Hong ZJ (2007) Inheritance and resistance to insects in $C r y I A(c)$ transgenic cabbage. Chin J Agr Biotechnol 4, 57-61.

31. Zhang L, Wu D, Zhang L, Yang C (2007) Agrobacterium-mediated transformation of Japanese lawngrass (Zoysia japonica Steud.) containing a synthetic cryIA $(b)$ gene from Bacillus thuringiensis. Plant Breed 126, 428-32.

32. Ivo NL, Nascimento CP, Vieira LS, Campos FAP, Aragão FJL (2008) Biolistic-mediated genetic transformation of cowpea (Vigna unguiculata) and stable
Mendelian inheritance of transgenes. Plant Cell Rep 27, 1475-83.

33. Spencer TM, O'Brien JV, Start WG, Adams TR (1992) Segregation of transgene in maize. Plant Mol Biol 18, 201-10.

34. Wan Y, Lemaux PG (1994) Generation of large numbers of independently transformed fertile barley plants. Plant Physiol 104, 37-48.

35. Somers DA, Torber KA, Pawlowski WP, Rines HW (1994) Genetic engineering of oat. In: Henry RJ, Ronald JA (eds) Improvement of cereal quality by genetic engineering. Plenum Press, New York, 37-46.

36. Altman DW, Benedict JH, Sach ES (1996) Transgenic plants for the development of durable insect resistance, a case study for cotton and Bacillus thuringiensis. Ann New York Acad Sci 792, 106-14.

37. Wu G, Cui H, Ye G, Xia Y, Sardana R, Cheng X, Li $\mathrm{Y}$, Altosaar I, et al (2002) Inheritance and expression of the crylAb gene in $\mathrm{Bt}$ (Bacillus thuringiensis) transgenic rice. Theor Appl Genet 104, 727-34.

38. Rashid B, Saleem Z, Husnain T, Riazuddin S (2008) Transformation and inheritance of Bt genes in Gossypium hirsutum. J Plant Biol 51, ), 248-54.

39. Sun W, Bernard C, Van de Cotte B, Van MM, Verbruggen $\mathrm{N}$ (2001) At-HSP17.6A, encoding a small heatshock protein in Arabidopsis can enhance osmotolerance upon overexpression. Plant $J$ 27, 407-15.

40. Wagner KU, McAllister K, Ward T, Davis B, Wiseman R, Hennighausen L (2001) Spatial and temporal expression of the Cre gene under the control of the MMTVLTR in different lines of transgenic mice. . Transgenic Res 10, 545-53.

41. Grandori C, Iritani B, Eisenman R (2001) Gene expression profiles at various stages of lymphomagenesis in Em-myc transgenic mice. Nat Genet 27, 57.

42. Amstutz U, Giger T, Champigneulle A, Philip JRD, Largiadèr CR (2006) Distinct temporal patterns of Transaldolase 1 gene expression in future migratory and sedentary brown trout (Salmo trutta). Aquaculture 260, 326-36.

43. Nystrom T, Neidhardt FC (1996) Effects of overproducing the universal stress protein UspA, in Escherichia coli $K-12$. J Bacteriol 178, 927-30.

44. Reinhardt D, Wittwer F, Mandel T, Kuhlemeier $C$ (1998) Localized upregulation of a new expansin gene predicts the site of leaf formation in the tomato meristem. Plant Cell 10, 1427-37.

45. Wang GL, Ruan DL, Song WY, Sideris S, Ronald PC (1996) The clones gene Xa 21, confers resistance to multiple Xanthomonas oryza pv. Oryzae isolates in transgenic plants. Mol Plant Microbe Interact 9, 850-5.

46. Boggs JZ, Loewy K, Bibee K, Heschel MS (2010) Phytochromes influence stomatal conductance plasticity in Arabidopsis thaliana. Plant Growth Regul 60, 77-81.

47. Bakhsh A, Shahzad K, Husnain T (2011) Variation in the spatio-temporal expression of insecticidal genes in 
cotton. Czech J Genet Plant Breed 47, 1-9.

48. Bakhsh A, Siddique S, Husnain T (2012) A molecular approach to combat spatio-temporal variation in insecticidal gene (Cry1Ac) expression in cotton. Euphytica 183, 65-74.

49. Xia L, Xu Q, Guo S (2005) Bt insecticidal gene and its temporal expression in transgenic cotton plants. Acta Agron Sin 31, 197-202.

50. Pasapula V, Shen G, Kuppu S, Paez-Valencia J, Mendoza M, Hou P, Chen J, Qiu X, Zhu L, Zhang X, Auld D, Blumwald E, Zhang H, Gaxiola R, Payton $\mathrm{P}$ (2011) Expression of an Arabidopsis vacuolar $\mathrm{H}^{+}$-pyrophosphatase gene (AVP1) in cotton improves drought- and salt tolerance and increases fibre yield in the field conditions. Plant Biotechnol J 9, 88-99.

51. McWilliams D (2003) Drought strategies for cotton. Cooperative Extension Service, College of Agriculture and Home Economics, Department of Extension Plant Sciences, New Mexico State Univ, Las Cruces, New Mexico, Circular 582.

52. Ihsan Ullah Rahman M, Ashraf M, Zafar Y (2008) Genotypic variation for drought tolerance in cotton (Gossypium hirsutum L.): Leaf gas exchange and productivity. Flora 203, 105-15.

53. Sulian LV, Yang A, Zhang K, Wang L, Zhang J (2007) Increase of glycinebetaine synthesis improves drought tolerance in cotton. Mol Breed 20, 233-48. 